\title{
Efeito da adição de resíduo de vidro em massa de cerâmica de alvenaria
}

\author{
Effect of addition of glass waste on \\ masonry ceramics
}

\author{
Alexandre Zaccaron ${ }^{1}$, Rafael Guelfi Frizzo ${ }^{1}$, \\ Elton Torres Zanoni ${ }^{1}$, Oscar Rubem Klegues Montedo ${ }^{1}$, \\ Adriano Michael Bernardin ${ }^{1}$, Michael Peterson ${ }^{1}$, \\ Fábio Rosso ${ }^{2}$, Vitor de Souza Nandi ${ }^{1,2}$.
}

\footnotetext{
${ }^{1}$ Programa de Pós-Graduação em Ciências e Engenharia de Materiais - PPGCEM, Universidade do Extremo Sul Catarinense - UNESC, Av. Universitária - 1105, CEP: 88806-000, Criciúma, SC, Brasil.

${ }^{2}$ Departamento de Engenharia Cerâmica, Centro Universitário Barriga Verde - UNIBAVE, Av. Valdemar Kleinubing 150 , CEP: 88845-000, Cocal do Sul, SC, Brasil.

e-mail: alexandrezaccaron@hotmail.com,rgfrizzo@gmail.com, elton.tz@hotmail.com,oscar.rkm@gmail.com, amb@unesc.net,mpe@unesc.net, fabiorosso@hotmail.com, vitorsnprof@gmail.com.
}

\section{RESUMO}

Este trabalho investigou o efeito da adição de resíduo de vidro para fabricação de cerâmica de alvenaria. Foram conformados corpos-de-prova cilíndricos de $27 \mathrm{~mm}$ de diâmetro por $45 \mathrm{~mm}$ de altura, a partir da massa padrão de uma indústria de cerâmica vermelha e outras 3 formulações $(5,10$ e 20\%) com incorporação de vidro, baseado em estudos apresentados na literatura. $\mathrm{O}$ tratamento térmico foi realizado em forno mufla em 3 temperaturas $\left(800,900\right.$ e $\left.1000{ }^{\circ} \mathrm{C}\right)$. As propriedades tecnológicas avaliadas foram: retração de secagem e de queima, absorção de água, perda ao fogo e resistência mecânica à compressão. Foi possível observar que a retração de secagem baixou de 7,9 para 5,9\% com o aumento do teor de vidro adicionado. A adição de resíduo de vidro à massa cerâmica não interferiu significativamente na retração de queima a 800 e $900{ }^{\circ} \mathrm{C}$, mas aumentou significativamente a $1000{ }^{\circ} \mathrm{C}$, assim como a absorção de água foi reduzida consideravelmente a $1000{ }^{\circ} \mathrm{C}$. A adição de resíduo de vidro reduziu a resistência à compressão das peças cerâmicas em até 4,4 $\mathrm{MPa}$, mas os valores encontrados ficaram dentro do estabelecido por norma. A composição com adição de $20 \%$ de resíduo de vidro sinterizada a $900{ }^{\circ} \mathrm{C}$ alcançou $6 \mathrm{MPa}$, valor superior ao 1,5 $\mathrm{MPa}$ estabelecido por norma a blocos de vedação. A $1000{ }^{\circ} \mathrm{C}$ foi observada a ocorrência de overfiring, que leva ao surgimento de bolhas e deformação. A adição de até $20 \%$ de resíduo de vidro à massa cerâmica para alvenaria sinterizada a $900{ }^{\circ} \mathrm{C}$ apresenta valores aceitáveis pela norma brasileira, das propriedades tecnológicas avaliadas, com a vantagem de reduzir a tendência ao surgimento de trincas de secagem e à variação dimensional, além de contribuir para a redução de uso de matérias-primas virgens e de se dar um destino racional a um resíduo.

Palavras-chave: cerâmica de alvenaria; resíduo de vidro; propriedades tecnológicas.

\section{ABSTRACT}

This work investigated the effect of the addition of glass waste to the manufacture of masonry ceramics. Was conformed cylindrical samples with $27 \mathrm{~mm}$ in diameter by $45 \mathrm{~mm}$ in height were made from the standard mass of a hard clay ceramic industry and other 3 formulations (5, 10 and $20 \%$ ) with glass incorporation, based on studies presented in the literature. The heat treatment was carried out in a muffle at three temperatures $\left(800,900\right.$ and $\left.1000{ }^{\circ} \mathrm{C}\right)$. The technological properties evaluated were: linear drying shrinkage and linear firing shrinkage, water absorption, fire loss and mechanical resistance to compression. It was observed that the drying retraction decreased from 7.9 to $5.9 \%$ with the increase of the glass content added. The addition of glass waste to the ceramic mass did not significantly interfere with the retraction of burning at 800 and $900{ }^{\circ} \mathrm{C}$, but increased significantly at $1000{ }^{\circ} \mathrm{C}$, as well as water absorption was reduced considerably at $1000{ }^{\circ} \mathrm{C}$. The addition of glass waste reduces the resistance to compression of the ceramic pieces by up to 4.4 $\mathrm{MPa}$, but the values found were within the established by norm. The composition with addition of $20 \%$ of sintered glass waste at $900{ }^{\circ} \mathrm{C}$ reached a value of $6 \mathrm{MPa}$, value greater than $1,5 \mathrm{MPa}$ for standard to hollow 
ceramic block for non-load-bearing. At $1000{ }^{\circ} \mathrm{C}$ was observed the occurrence of overfiring, which leads to the appearance of bubbles and deformation. The addition of up to $20 \%$ of glass residue to the ceramic mass for sintered masonry at $900{ }^{\circ} \mathrm{C}$ presents values acceptable by the Brazilian standard, of the technological properties evaluated, with the advantage of reducing the tendency to cracks and dimensional variation, besides contributing to the reduction of the use of virgin raw materials and of giving a sustainable destination to a waste.

Keywords: masonry ceramics, glass waste, technological properties.

\section{INTRODUÇÃO}

O progresso econômico tem aumentado a quantidade de resíduos gerados, muitos dos quais são difíceis de serem deteriorados naturalmente. Esse crescente volume de resíduos oriundos das mais diversas atividades econômicas causa preocupações relacionadas à sua disposição, no qual o acúmulo desses em depósitos controlados, mesmo que adequadamente preparados e mantidos, é uma solução cada vez menos aceita pela sociedade. O reaproveitamento do resíduo é uma forma de retardar ou até mesmo eliminar sua disposição final em depósitos, tais como aterros sanitários [1-3].

Os vidros utilizados para embalagens, como garrafas, é um material amorfo, de elevada resistência química, não poroso e frágil, composto principalmente de sílica. Ao final de seu uso, utensílios a base de vidro são descartados; entretanto, a maioria dos vidros comuns são totalmente recicláveis e podem ser reutilizados e incorporados a outros processos fabris [4-6].

As taxas de geração de resíduos urbanos em todo o mundo geram milhões de toneladas de vidro por ano [7]. Apesar de serem reaproveitados no processo de fabricação de novas garrafas, os vidros de envasamento ainda geram problemas ambientais, devido a não haver uma gestão adequada desses resíduos, o que consequentemente acarreta quantidades expressivas a serem depositadas nos aterros sanitários. Para estes casos, torna-se necessário encontrar alternativas tecnológicas viáveis que permitam a reciclagem desses vidros de forma econômica e sustentável.

Sabe-se que a indústria de cerâmica vermelha possui potencial para utilização e valorização de diferentes resíduos, que geridos da maneira correta, proporcionam ganhos consideráveis na sua fabricação [8]. Em contrapartida, isso pode prolongar o tempo de vida dos depósitos de matérias-primas brutas, além da utilização de materiais que, em geral, viriam a ser descartado no meio ambiente, contribuindo para a viabilidade econômica da reciclagem de alguns resíduos sólidos industriais [9]. Tecnicamente falando, a incorporação de resíduos na fabricação de blocos cerâmicos é uma alternativa capaz de encapsulamento desses, unido as questões ambientais que tratam da quantidade de matérias-primas disponíveis na natureza. Tal tema vem sendo proposto por estudiosos ao redor do mundo com muita frequência [10-17].

A incorporação de resíduo de vidro a produtos fabricados à base de argila é uma alternativa considerada natural devido à compatibilidade entre a composição química destes produtos e a do vidro, que é essencialmente formada por sílica $\left(\mathrm{SiO}_{2}\right)$, com um pequeno percentual de óxido de sódio $\left(\mathrm{Na}_{2} \mathrm{O}\right)$ e de óxido de cálcio $(\mathrm{CaO})$. Muitos estudos têm sido realizados no mundo todo, visando a incorporação desse resíduo na massa cerâmica para melhoria das propriedades tecnológicas dos produtos cerâmicos [18-20].

Além das questões ambientais que envolvem a disposição dos resíduos de vidro, existe a necessidade da fabricação de produtos cerâmicos dentro de um padrão estabelecido de qualidade. Portanto, considerandose a compatibilidade destes materiais (argila e vidro), esse estudo visa avaliar as interações do vidro na matriz cerâmica e o efeito da adição do resíduo de vidro nas propriedades tecnológicas de uma massa de cerâmica de alvenaria.

\section{MATERIAIS E MÉTODOS}

A argila utilizada no experimento laboratorial foi cedida por uma indústria de cerâmica vermelha sul catarinense. A massa padrão, composta por uma mistura de argilas, foi coletada diretamente do box de armazenamento da cerâmica, onde foram retirados aproximadamente $100 \mathrm{~kg}$ de cinco pontos diferentes. Essas amostras passaram pelo processo de quarteamento, homogeneizadas e reduzidas para um volume de $30 \mathrm{~kg}$. O vidro utilizado no estudo foi cedido pela Fundação Municipal do Meio Ambiente de Morro da Fumaça - FUMAF, que dispõe de uma central de coleta de resíduos recicláveis. Cerca de $10 \mathrm{~kg}$ de vidro de garrafa foram beneficiados no Laboratório Técnico de Cerâmica Vermelha, Labcer, em Morro da Fumaça, SC. As garrafas foram limpas para remoção dos rótulos, quebradas em cacos e em seguida processadas em cilindro laboratorial, marca Bertan, para fragmentação e posteriormente passada em peneira 10 mesh (2 mm). A granulometria do resíduo de vidro foi medida através da distribuição granulométrica em peneiras de malhas 16,40 e 80 
mesh. Optou-se em utilizar grãos em uma faixa de 100 a $1000 \mu \mathrm{m}$ no estudo para se avaliar o efeito na secagem e nas propriedades finais, em comparação ao pó de vidro tipicamente empregado em matriz cerâmica.

A determinação da análise química da massa padrão e do resíduo de vidro foi realizada por espectrometria de fluorescência de raios X em um espectrômetro de raios X (Philips, modelo: PW2400) por dispersão de comprimento de onda (WDXRF).

As formulações foram elaboradas com base no trabalho de Phonphuak, Kanyakam \& Chindaprasirt (2016) [21]. A Tabela 1 mostra as formulações estudadas.

Tabela 1: Formulações estudadas neste trabalho.

\begin{tabular}{l|l|l|l|l}
\hline \multirow{2}{*}{ Matéria-Prima } & \multicolumn{4}{|c}{ Formulações (\% massa) } \\
\cline { 2 - 5 } & STD & F1 & F2 & F3 \\
\hline Argila & 100 & 95 & 90 & 80 \\
\hline Vidro & - & 5 & 10 & 20 \\
\hline
\end{tabular}

A etapa de mistura e conformação dos corpos-de-prova foi realizada no Laboratório de Materiais Cerâmicos Cocal do Sul - LaMaCC. A preparação foi efetuada através de um misturador de rosca helicoidal. Posteriormente, a massa foi descansar deixada em repouso durante $24 \mathrm{~h}$ para homogeneização da umidade. Os corpos-de-prova (30 para cada formulação) foram preparados por extrusão (sem vácuo) por êmbolo: funil com redução de $250 \mathrm{~mm}$ para $27 \mathrm{~mm}$ com ângulo de $45^{\circ}$, com pressão constante. Todas as peças foram pesadas (balança marca Marte AD 5002, de precisão 0,01 g) e medidas com paquímetro (Digmess digital com precisão de $0,01 \mathrm{~mm}$ ). Em seguida, todas as peças foram para secagem em estufa elétrica (marca DeLeo), a uma temperatura de $65 \pm 5^{\circ} \mathrm{C}$ durante $24 \mathrm{~h}$ e por mais $12 \mathrm{~h}$ a $100 \pm 5^{\circ} \mathrm{C}$ para remoção total da umidade, sendo posteriormente pesadas e medidas.

Após a verificação dos dados das peças cruas, as formulações foram sinterizadas em forno mufla elétrico (Jung, Modelo 7012), com taxa de aquecimento de $2{ }^{\circ} \mathrm{C} / \mathrm{min}$, patamar de $120 \mathrm{~min}$ em três temperaturas, 800,900 e $1000{ }^{\circ} \mathrm{C}$. Todas as peças novamente foram medidas e pesadas para se realizar o ensaio de retração de queima (RQ).

Ensaios de absorção de água, perda ao fogo e resistência mecânica à compressão foram realizados. O ensaio de absorção de água foi executado de acordo com a norma ABNT NBR 15270-3 [22]. Que consiste em pesar a amostra seca, e depois submetê-la em banho de imersão com água fervente por $2 \mathrm{~h}$. Após o banho retira-se o excesso de umidade com o auxílio de um pano umedecido e efetua-se a pesagem; a variação percentual de massa ocorrida nas peças em decorrência deste ensaio representa a absorção de água (AA) da formulação. A perda ao fogo $(\mathrm{PF})$ corresponde à quantidade de material que volatilizou em virtude das decomposições que ocorreram durante as etapas de aquecimento e queima no forno. Consiste em pesar os corpos de prova secos e depois de queimados, onde após a queima são resfriados em temperatura ambiente. $\mathrm{O}$ ensaio de resistência mecânica à compressão (RMC) foi realizado no Labcer - Laboratório Técnico de Cerâmica Vermelha, com o auxílio de uma Máquina Universal de Ensaios (EMIC DL-20000) de acordo com a norma ABNT NBR 15270-3 [22].

Foi realizada a caracterização mineralógica por difratometria de raios X (Shimadzu XRD 6000) da massa padrão (STD) e das composições $\mathrm{F} 1, \mathrm{~F} 2$ e F3 a $900{ }^{\circ} \mathrm{C}$, no intuito de constatar alguma alteração nas fases cristalinas devido à variação composicional. Esse ensaio também foi realizado para a adição de $20 \%$ de resíduo (F3) a 800 e $1000{ }^{\circ} \mathrm{C}$, com intuito de se avaliar o efeito da temperatura. Para investigação dos óxidos presentes nas matérias-primas, a argila e o resíduo foram analisados quimicamente, mediante espectrometria de fluorescência de raios X (FRX), realizada em um espectrômetro Bruker (S2 Ranger).

Para se verificar a interação entre a massa cerâmica e o resido de vidro, usou-se um microscópio eletrônico de varredura (MEV, Zeiss EVO MA10) e um microscópio ótico (Olympus, BX41M-LED), respectivamente nos laboratórios de Cerâmica Técnica (CerTec) e de Microscopia do Parque Científico e Tecnológico - Iparque/Unesc, nos corpos-de-prova da formulação F3 a 800, 900 e $1000{ }^{\circ} \mathrm{C}$.

\section{RESULTADOS E DISCUSSÃO}

A Tabela 2 mostra a composição química do resíduo de vidro e da argila usados neste estudo. 
Tabela 2: Análise química do resíduo de vidro e da argila usados no estudo.

\begin{tabular}{c|c|c}
\hline Óxidos & Resíduo de vidro (\%) & Argila (\%) \\
\hline $\mathrm{Al}_{2} \mathrm{O}_{3}$ & 1,94 & 18,24 \\
\hline $\mathrm{CaO}$ & 10,50 & 0,14 \\
\hline $\mathrm{Fe}_{2} \mathrm{O}_{3}$ & 1,06 & 4,95 \\
\hline $\mathrm{K}_{2} \mathrm{O}$ & 0,31 & 1,72 \\
\hline $\mathrm{MgO}$ & 0,62 & 0,56 \\
\hline $\mathrm{MnO}$ & $<0,05$ & $<0,05$ \\
\hline $\mathrm{Na}_{2} \mathrm{O}$ & 13,90 & 0,21 \\
\hline $\mathrm{P}_{2} \mathrm{O}_{5}$ & $<0,05$ & 0,08 \\
\hline $\mathrm{SiO}_{2}$ & 70,81 & 65,63 \\
\hline $\mathrm{TiO}_{2}$ & 0,06 & 0,94 \\
\hline $\mathrm{BaO}_{\mathrm{Co}}$ & $<0,1$ & - \\
\hline $\mathrm{Co}_{2} \mathrm{O}_{3}$ & $<0,1$ & - \\
\hline $\mathrm{Cr}_{2} \mathrm{O}_{3}$ & 0,23 & - \\
\hline $\mathrm{PbO}^{2}$ & $<0,1$ & - \\
\hline $\mathrm{SrO}_{\mathrm{ZnO}}$ & $<0,1$ & - \\
\hline $\mathrm{ZrO}_{2}+\mathrm{HfO}_{2}$ & $<0,1$ & - \\
\hline $\mathrm{P} . \mathrm{F}$ & $<0,1$ & \\
\hline
\end{tabular}

P.F: Perda ao fogo

O resíduo de vidro em questão é do tipo sódio-cálcico. É possível observar a predominância de sílica $\left(\mathrm{SiO}_{2}\right)$ na composição do vidro, sendo a matéria-prima básica com função vitrificante. Sódio $\left(\mathrm{Na}_{2} \mathrm{O}\right)$ e cálcio $(\mathrm{CaO})$ estão em teores que caracterizam o vidro estudado. Quanto à relevância do estudo, a presença majoritária destes óxidos pode melhorar a qualidade do material estudado, principalmente na resistência mecânica, já que são óxidos fundentes relacionados à vitrificação do material [23].

A Figura 1 apresenta a distribuição granulométrica do resíduo estudado.

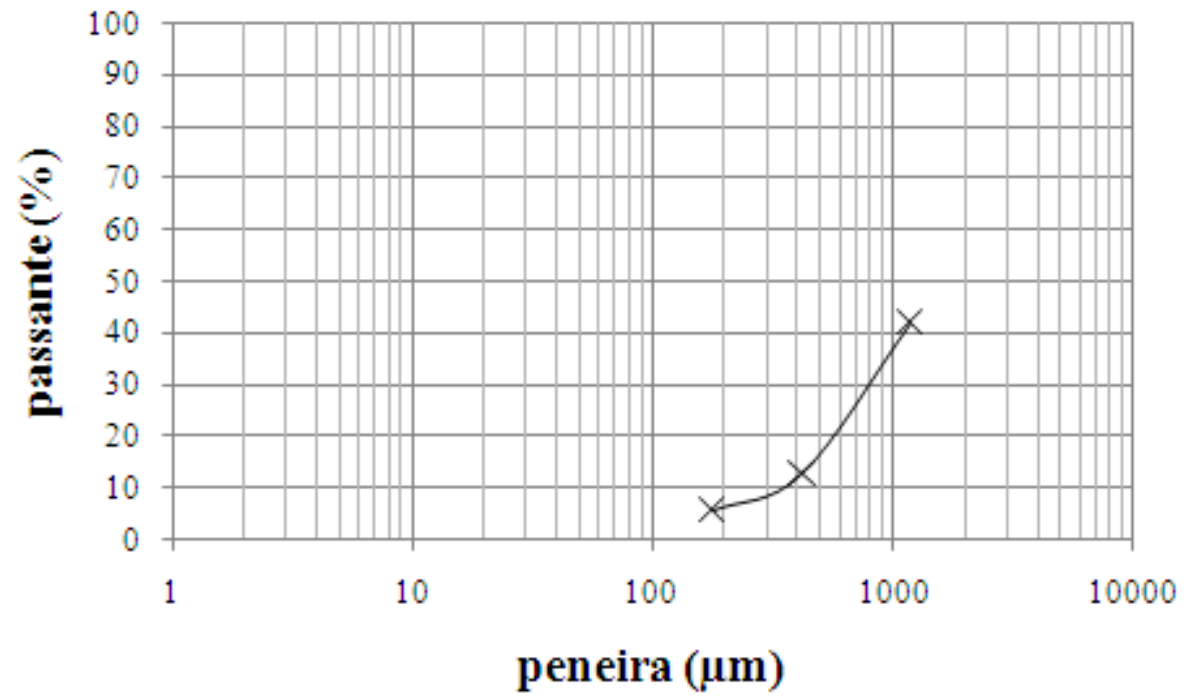

Figura 1: Distribuição granulométrica do resíduo de vidro usado no estudo.

É possível observar que mais da metade das partículas $(58,1 \%)$ ficaram retidas na malha 16 MESH 
(1190 $\mu \mathrm{m})$, mostrando que a granulometria do resíduo é grosseira. Ainda, 29,1\% das partículas ficou retida na malha $40 \mathrm{MESH}(420 \mu \mathrm{m})$ e apenas $7 \%$ do resíduo ficou retido na malha $80 \mathrm{MESH}(177 \mu \mathrm{m})$, tendo apenas menos de $6 \%$ passante nessa mesma peneira.

Os óxidos dos elementos químicos mostrados na Tabela 2, em sua forma mais estável, estão presentes nas fases cristalinas identificadas no difratograma de raios X da Figura 2 para a argila, onde é possível observar que a massa utilizada como matriz cerâmica apresenta majoritariamente as seguintes fases cristalinas: quartzo- $\alpha\left(\mathrm{SiO}_{2}\right.$, cartão JCPDS no 46-1045), microclínio (KAlSi ${ }_{3} \mathrm{O}_{8}$, cartão JCPDS $\mathrm{n}^{\circ}$ 19-932) e caulinita $\left(\mathrm{CaAl}_{2} \mathrm{Si}_{2} \mathrm{O}_{8} \cdot 4 \mathrm{H}_{2} \mathrm{O}\right.$, cartão JCPDS $\left.\mathrm{n}^{\circ} 20-0452\right)$. Este difratograma é característico de uma argila tipicamente usada na fabricação de cerâmica vermelha.

A Figura 3 mostra o difratograma de raios $\mathrm{X}$ do resíduo de vidro utilizado no estudo, onde apresenta ser um material totalmente amorfo, característico de um vidro.

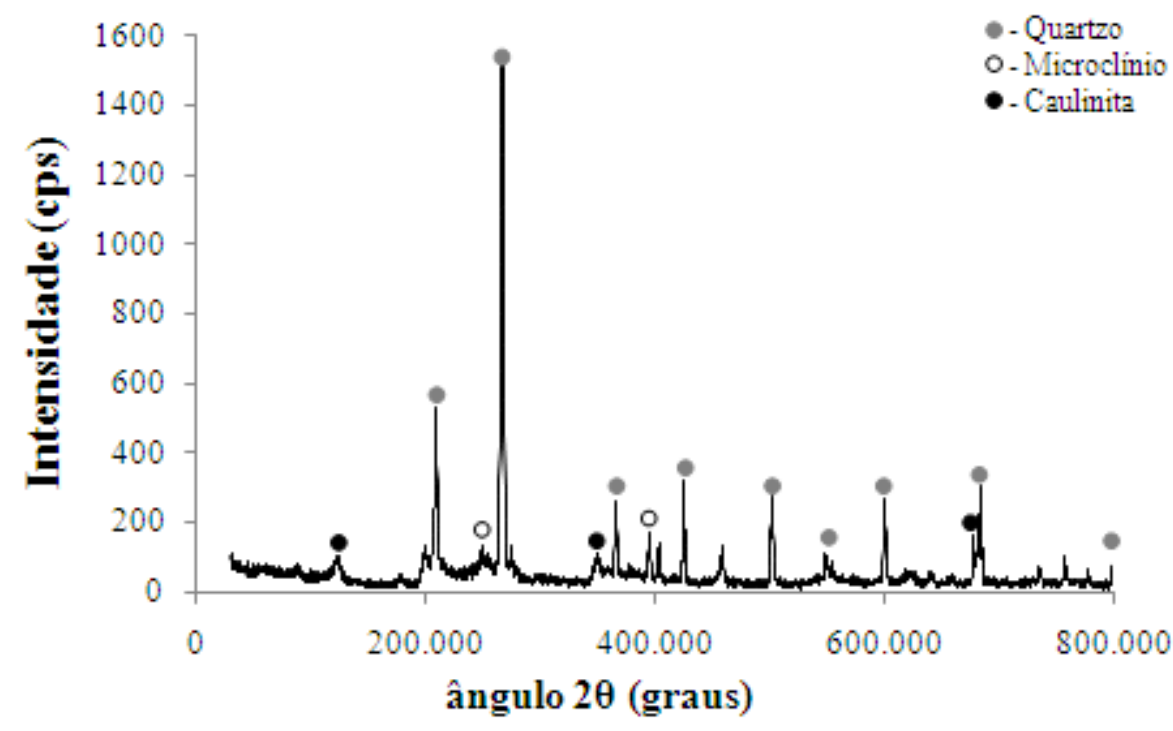

Figura 2: Difratograma de raios $X$ da argila utilizada como matriz no estudo.

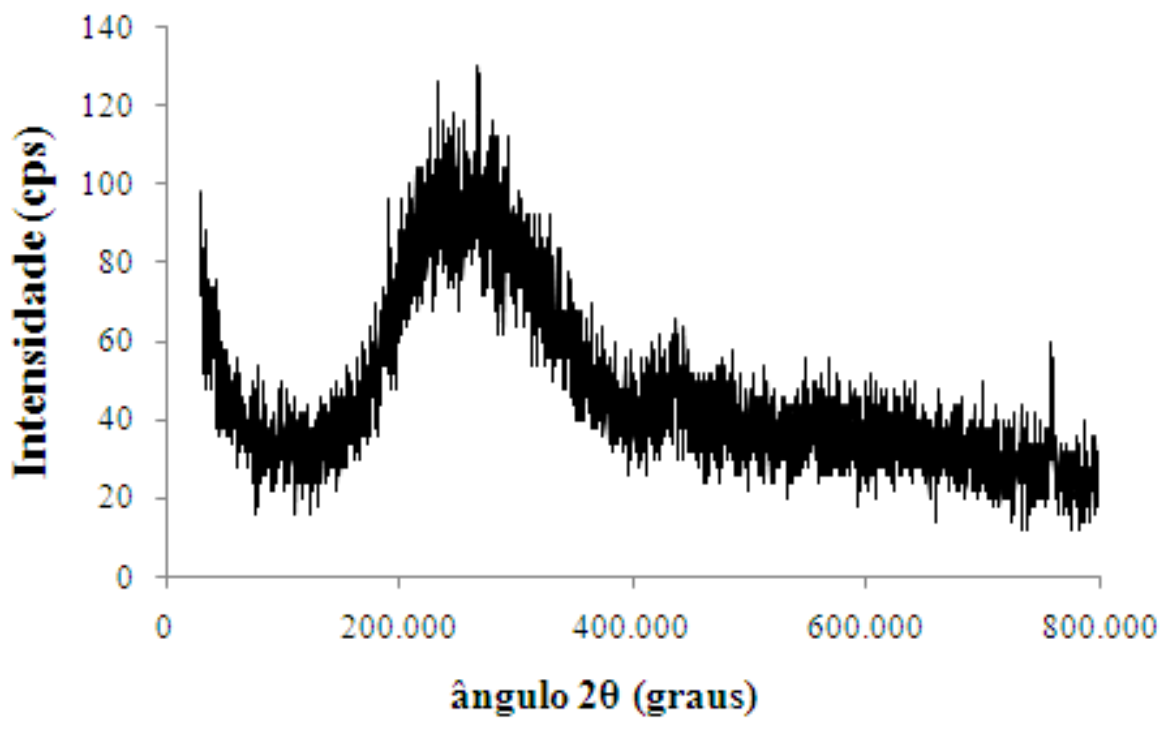

Figura 3: Difratograma de raios $\mathrm{X}$ do vidro utilizado.

Nas Figuras 4 e 5 são apresentados os resultados das fases cristalinas das composições utilizadas no estudo. A Figura 4 mostra os difratogramas de raios $\mathrm{X}$ dos corpos de prova queimados a $900{ }^{\circ} \mathrm{C}$ com diferentes teores de vidro incorporado. A Figura 5 apresenta os difratogramas de raios $\mathrm{X}$ dos corpos-de-prova quei- 
mados a 800, 900 e $1000{ }^{\circ} \mathrm{C}$ com adição de $20 \%$ de resíduo de vidro (F3).

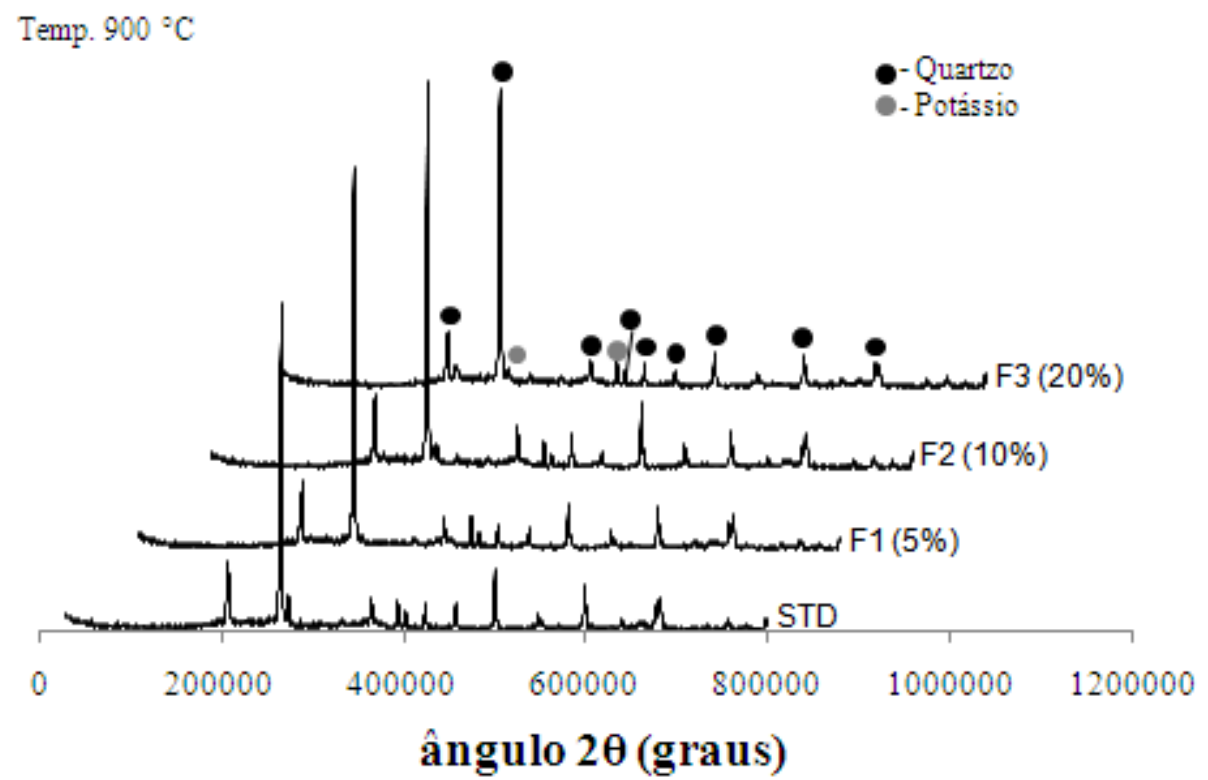

Figura 4: Difratogramas de raios $\mathrm{X}$ dos corpos-de-prova queimados a $900{ }^{\circ} \mathrm{C}$ a diferentes teores de vidro incorporado.

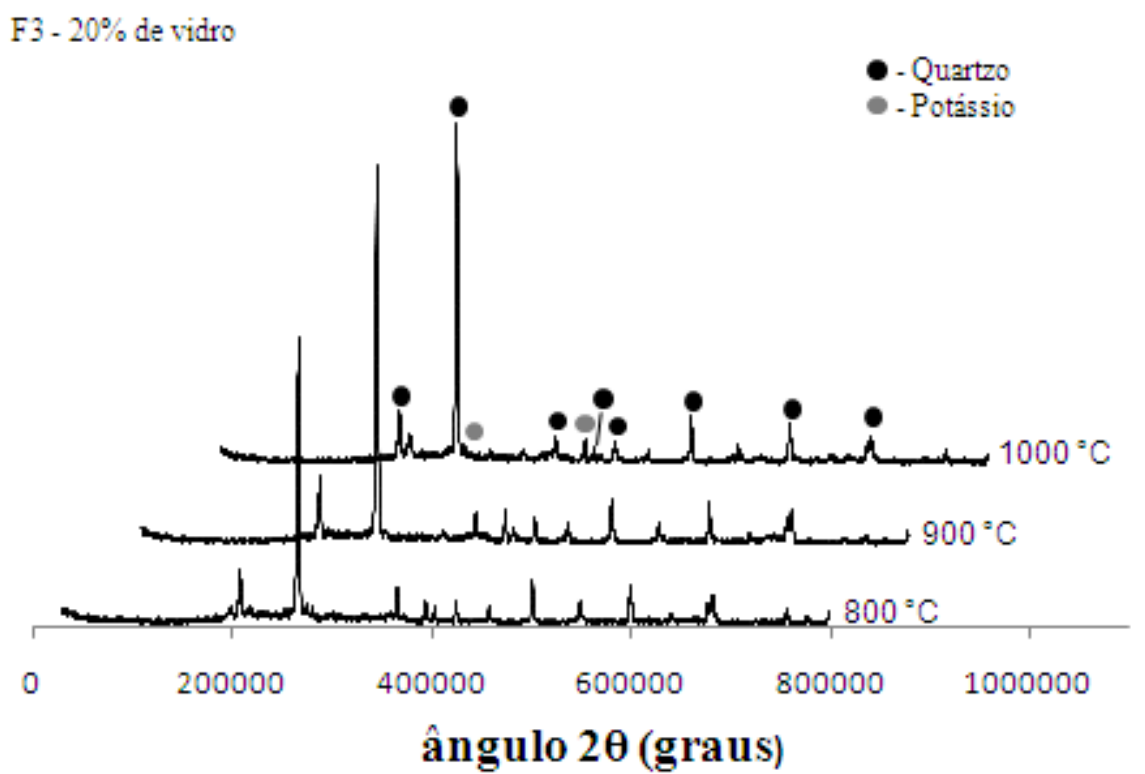

Figura 5: Difratogramas de raios $X$ dos corpos-de-prova queimados a 800, 900 e $1000{ }^{\circ} \mathrm{C}$ com adição de $20 \%$ de vidro (F3).

Pode-se observar, a partir da análise destas figuras, que as amostras apresentaram majoritariamente as seguintes fases cristalinas: quartzo- $\alpha\left(\mathrm{SiO}_{2}\right.$, cartão JCPDS no 46-1045) e microclínio ( $\mathrm{KAlSi}_{3} \mathrm{O}_{8}$, cartão JCPDS n ${ }^{\circ}$ 19-932). As quantidades de vidro adicionadas à matriz cerâmica não interferiram em suas fases cristalinas, mantendo as fases de origem de cada composto. Isto é, não se pode associar qualquer formação de nova fase cristalina nos teores de adição de resíduo e temperaturas estudados.

As Figuras 6 e 7 mostram a curva de Bigot e a retração de secagem em função do teor de resíduo de vidro adicionado. 


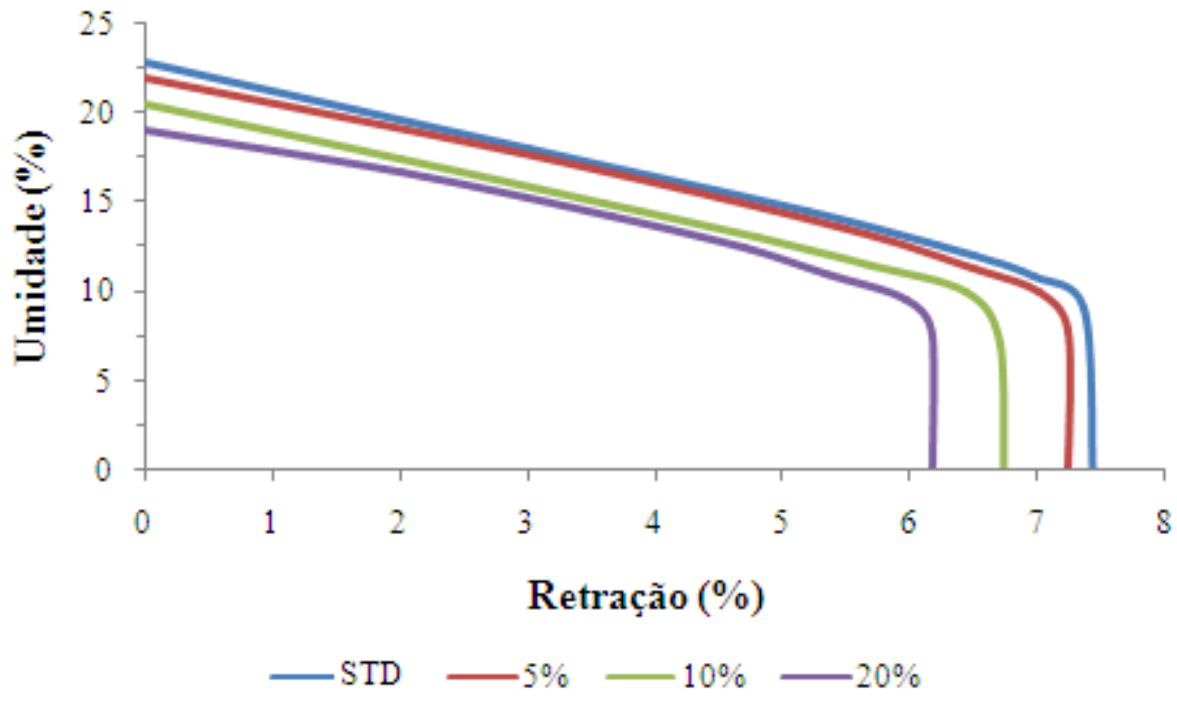

Figura 6: Curva de Bigot das amostras estudadas.

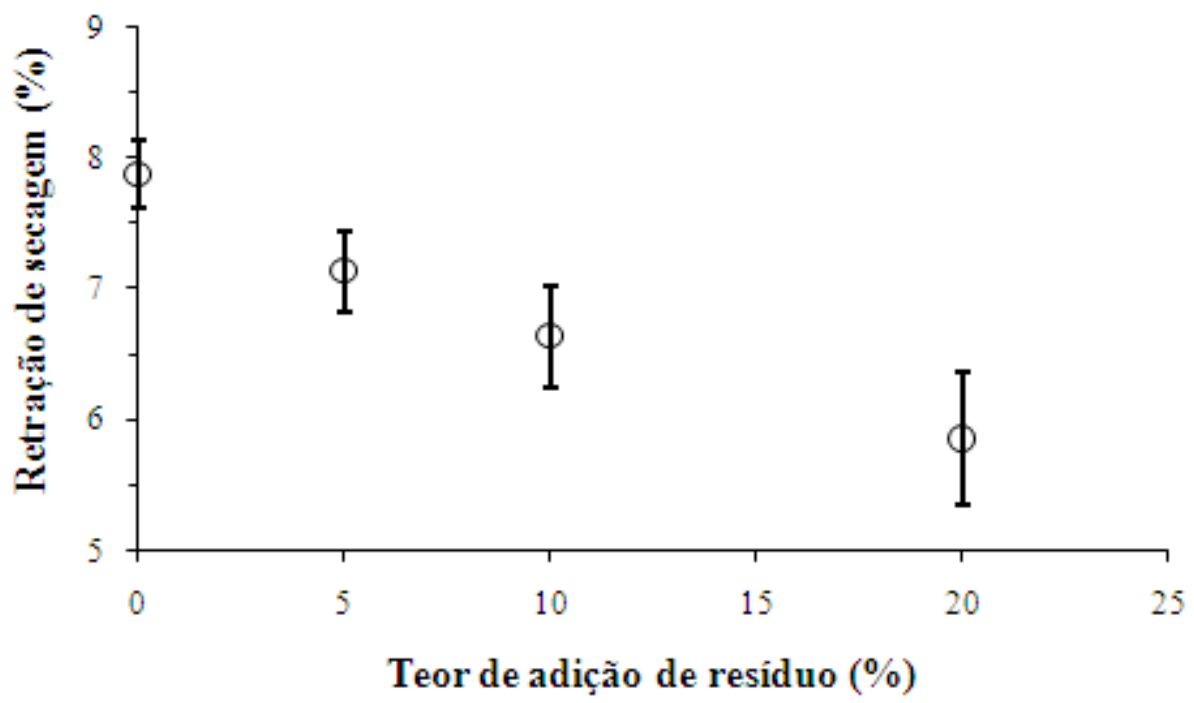

Figura 7: Retração de secagem em função do teor de resíduo de vidro adicionado.

A curva de Bigot descreve a evolução da retração de secagem em função da perda de água de conformação [24]. Observa-se que, com a adição de vidro à massa cerâmica, ocorre uma diminuição da umidade das composições e consequentemente uma redução da retração de secagem. Essa redução, de 7,8 \% para a formulação STD (0\% de adição de resíduo de vidro) para aproximadamente $6 \%$ com $20 \%$ de resíduo de vidro incorporado, deve-se ao comportamento do vidro na secagem, que não sofre variações dimensionais significativas a baixa temperatura. Ao ser eliminada a água, ocorre uma aproximação das partículas em consequência das forças de atração eletrostática, provocando enxugamento do material [17]. Isto está demonstrado na Fig. 7, onde, para uma maior quantidade de resíduo, menor a retração do corpo cerâmico. O resíduo incorporado a massa cerâmica é formado principalmente por sílica, que devido ao seu caráter inerte tende a diminuir a retração linear [17]. O uso de granulometrias com percentual maior que $1000 \mu \mathrm{m}$, tende auxiliar, inclusive, na diminuição da possibilidade de trincas na secagem forçada em estufas e secadores rápidos, onde há maior incidência de perdas no processo, pois ajudam no escoamento da umidade entre os grãos, devido ao fato de não haver um perfeito empacotamento. O comportamento de secagem vem sendo discutido com muito mais intensidade nos últimos anos, por ser uma das etapas mais complicadas e difíceis de se executar, principalmente com argilas mais plásticas que necessitam da maior quantidade de água para que possam ser moldadas [25,26]. Esse fato acarreta em um maior custo de secagem, bem como na probabilidade do surgimento de trincas. O resíduo de vidro nesta etapa do processo contribuiu significativamente na secagem, pois 
aumenta a capilaridade da massa.

$\mathrm{Na}$ queima, ao contrário, a retração aumentou com o aumento do teor de adição do resíduo de vidro, como pode ser observado na Figura 8.

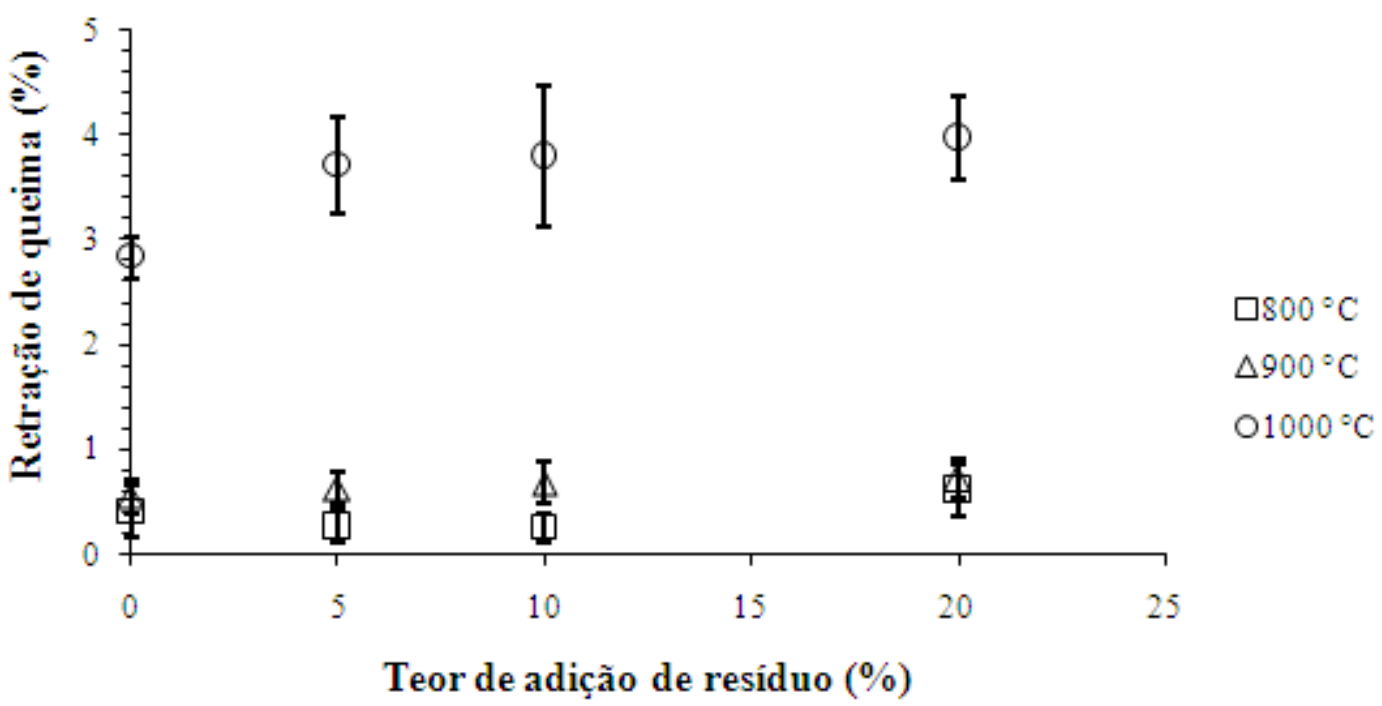

Figura 8: Retração de queima das formulações estudadas.

O gráfico mostra pouca alteração na retração de queima nas temperaturas de 800 e $900{ }^{\circ} \mathrm{C}$. A $1000{ }^{\circ} \mathrm{C}$ a retração de queima é maior. Pode-se dizer que nesta temperatura houve grande quantidade de fase líquida presente, que favorece a sinterização. $\mathrm{O}$ aumento do teor de resíduo de vidro adicionado tem efeito similar.

O aumento da retração de queima com a elevação da temperatura e do teor de resíduo adicionado teve efeito nas propriedades tecnológicas dos materiais obtidos.

A Figura 9 ilustra os resultados de absorção de água. Pode-se observar que há uma diminuição dessa propriedade com o aumento da temperatura e do teor de resíduo de vidro adicionado.

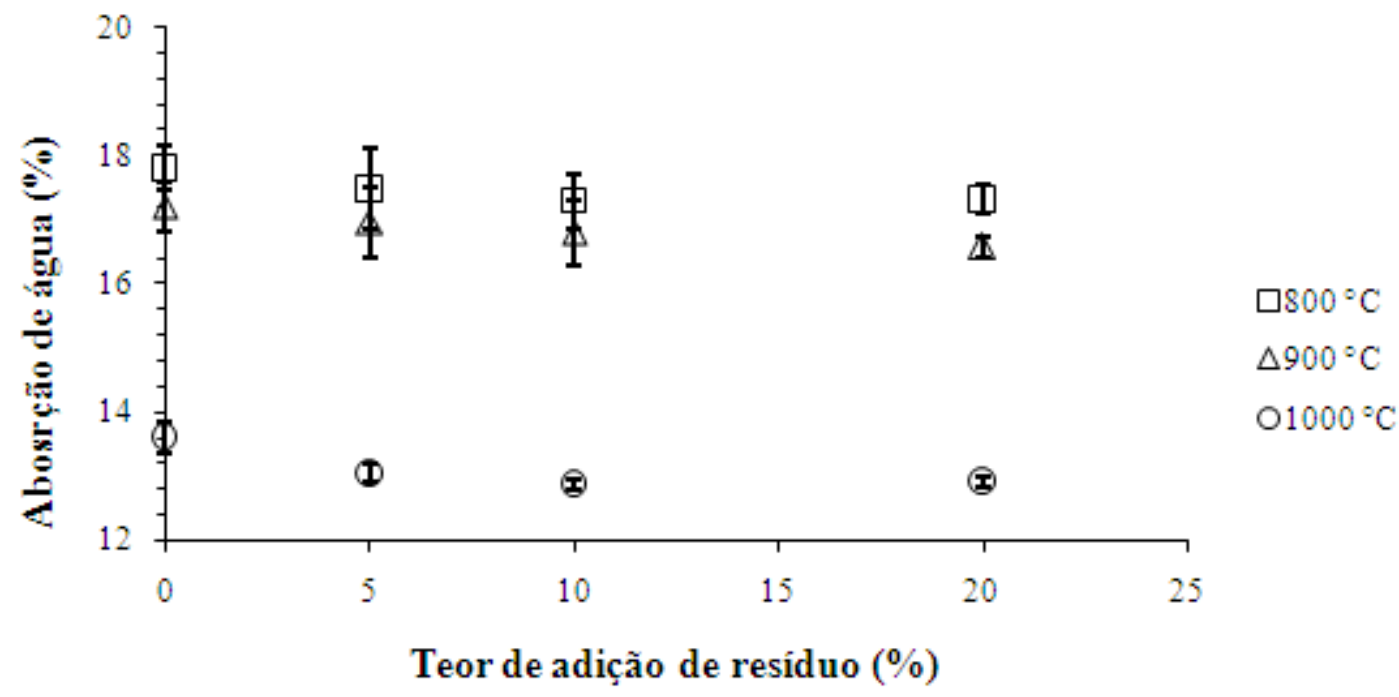

Figura 9: Absorção de água em função do teor de adição de resíduo de vidro.

O aumento da temperatura tende a reduzir a absorção de água do corpo cerâmico. Este comportamento é conseqüência do aumento da retração de queima, unido a formação de fases líquidas, pois quanto maior a temperatura de queima maior será o amolecimento do vidro incorporado, que tende a diminuir a porosidade 
das amostras, fazendo então, que haja menos espaços para o alojamento da água no interior das peças cerâmicas. Tal fenômeno também observado na literatura [27,28]. Importante destacar que a ABNT 15270 [29] determina limites mínimos e máximos para a absorção de água, pois o corpo cerâmico pode sofrer determinadas patogêneses relativas a essa propriedade.

A Figura 10 apresenta o gráfico com os resultados de perda ao fogo, que é a eliminação de materiais voláteis durante o processo de queima dos corpos-de-prova.

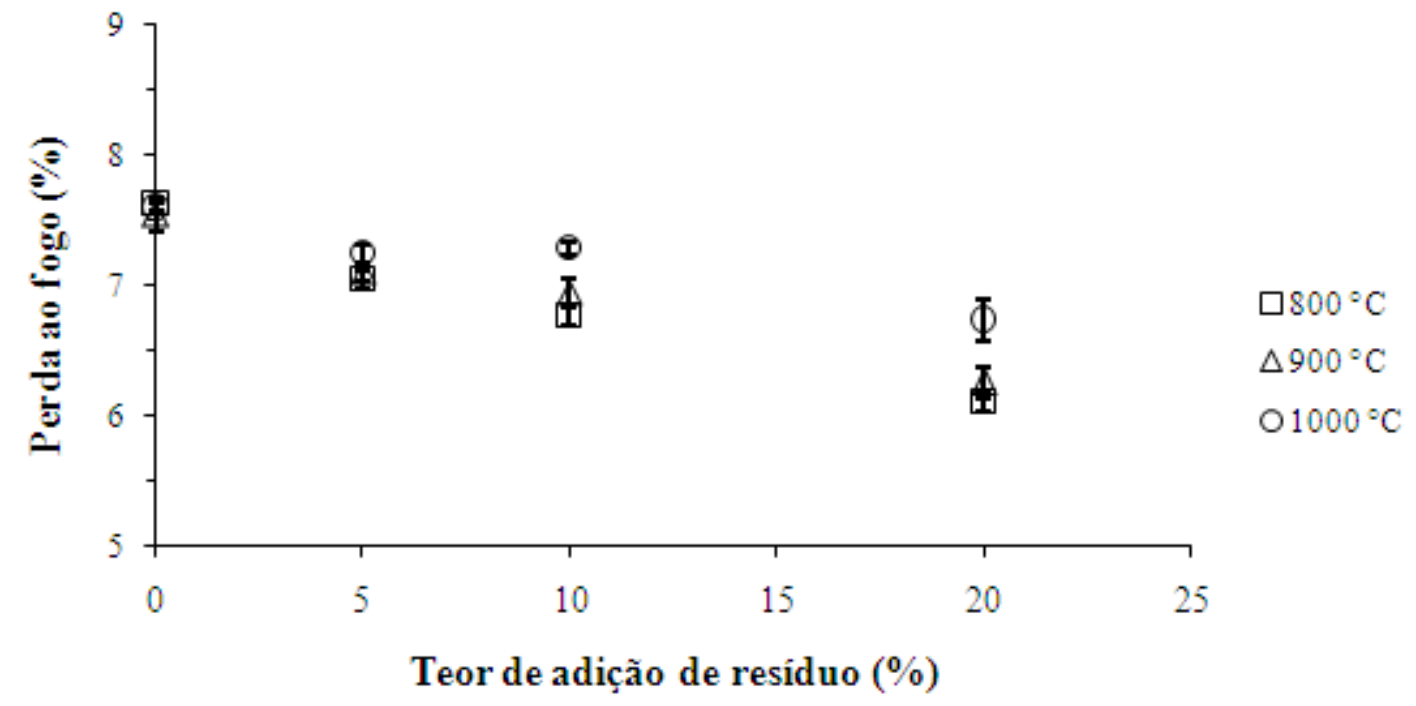

Figura 10: Perda ao fogo das formulações estudadas.

É possível interpretar que há redução da liberação de materiais voláteis à medida que aumenta o teor de vidro incorporado. Para a formulação STD ( $0 \%$ de adição), praticamente não houve variação nas três temperaturas; isso acontece, pois os argilominerais sofrem algumas transformações significativas em temperaturas abaixo das avaliadas, onde aquecidos até $150{ }^{\circ} \mathrm{C}$ perdem água dos poros e a água adsorvida, e a partir de $400{ }^{\circ} \mathrm{C}$ ocorre a expulsão da água ligada estruturalmente sob forma de grupos $\mathrm{OH}-$, concluindo que nas temperaturas usadas para queima não haviam mais voláteis em quantidades expressivas para diferenciarem entre si [30]. Com o aumento de resíduo incorporado, têm-se uma menor quantia de argilominerais sofrendo essas transformações. Em contrapartida a isso, as amostras tiveram as maiores perdas de voláteis com a adição de vidro, devido ao fato do vidro reagir com as altas temperaturas, ultrapassando as ideais para sinterização. Observa-se que as amostragens sinterizadas a $1000{ }^{\circ} \mathrm{C}$ apresentaram perdas ao fogo superiores às demais temperaturas, fenômeno evidenciado na formulação com $20 \%$ de teor de vidro.

$\mathrm{O}$ efeito da temperatura e do teor de resíduo de vidro adicionado na resistência mecânica à compressão é ilustrado na Figura 11. A resistência à compressão tende a diminuir com a incorporação do vidro. $\mathrm{O}$ aumento de temperatura acaba resultando em percentuais mais elevados de resistência, aproximadamente 3 $\mathrm{MPa}$, fato que ocorre porque há maior interação entre a matriz cerâmica e o reforço (vidro). Porém, com o aumento de adição do vidro, ocorre redução na resistência da peça, possivelmente devido ao da utilização de granulometria em faixas entre 100 e $1100 \mu \mathrm{m}$, o que tende a necessitar de maior energia para fundir-se completamente. 


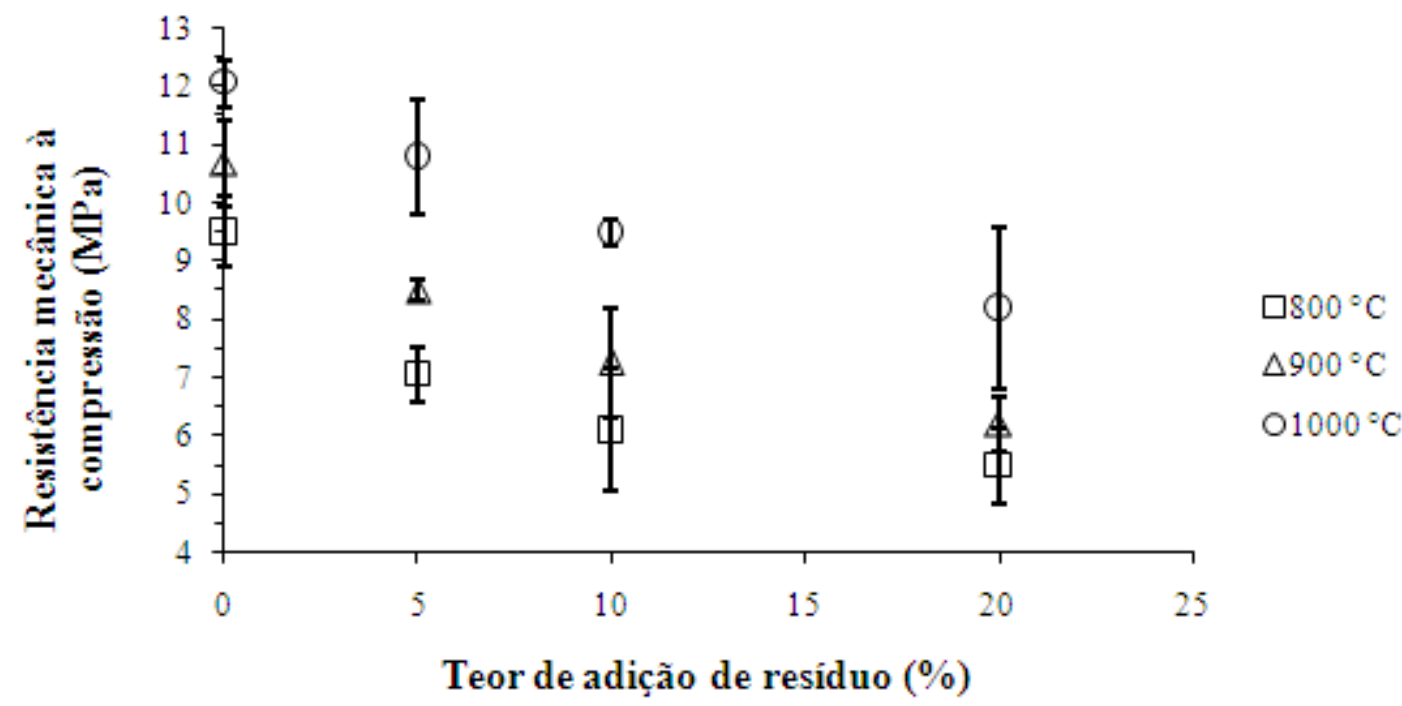

Figura 11: Resistência mecânica à compressão das formulações estudadas.

Se analisarmos a $900{ }^{\circ} \mathrm{C}$, que é usualmente a temperatura empregada na indústria de cerâmica vermelha, entre 0 e $20 \%$ de vidro incorporado, há redução de 4,4 MPa, e o limite que a norma estabelece é que o produto cerâmico tenha uma resistência mínima de 1,5 MPa [29].

A Figura 12(a) apresenta o resultado de MEV da formulação $\mathrm{F} 3$ a $800^{\circ} \mathrm{C}$, onde é possível observar que não houve uma adequada interação entre os dois materiais em alguns pontos. Diferentemente, a 900 e $1000{ }^{\circ} \mathrm{C}$, Figuras 12(b) e 12(c), observa-se maior interação entre os componentes cerâmicos, mostrando-se maior homogeneidade entre os distintos materiais, mostrando que o vidro fundiu a argila durante o processo de sinterização. A $1000{ }^{\circ} \mathrm{C}$ observa-se a liberação de gases durante o processo de sinterização, comprovado pela origem de poros na formação de fase líquida observada em alguns pontos da figura.

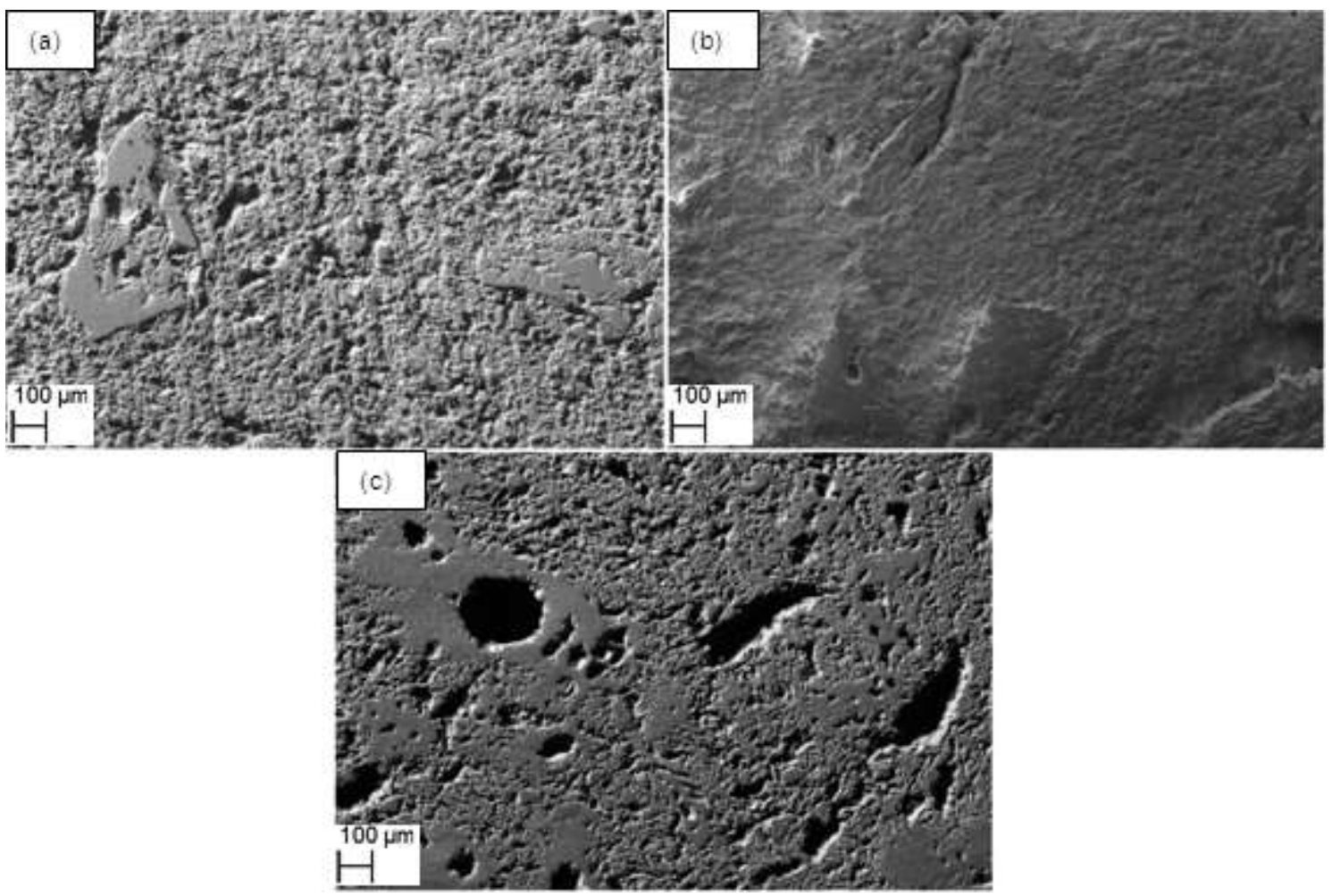

Figura 12: Imagens obtidas por MEV da formulação F3: (a) $800{ }^{\circ} \mathrm{C}$, (b) $900{ }^{\circ} \mathrm{C}$ e (c) $1000{ }^{\circ} \mathrm{C}$.

Este fenômeno também foi observado na superfície da peça, como é mostrada na Figura 13. Esta porosidade em temperaturas mais altas pode ser resultante da etapa de compactação e gerada no próprio proces- 
so de queima. Este comportamento também pode ser explicado pelo fenômeno denominado de porosidade por overfiring, que ocorre quando um material é queimado a uma temperatura acima da necessária para produzir uma fase líquida. O resultado deste fenômeno é o surgimento de deformações, bolhas ou poros [27,3133].

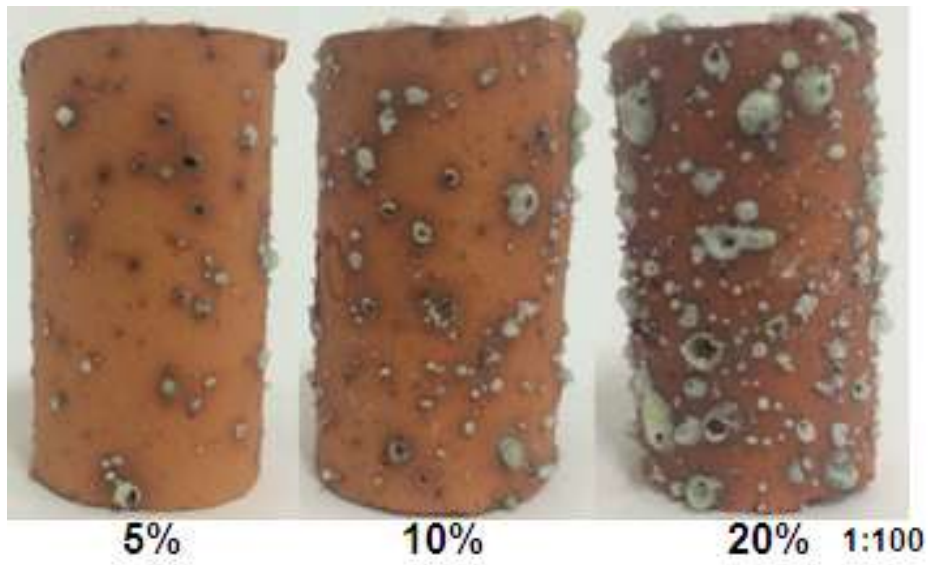

Figura 13: Imagem dos corpos-de-prova queimados a $1000^{\circ} \mathrm{C}$.

A Figura 14 apresenta uma imagem em corte transversal dos corpos-de-prova, no qual faz-se a análise dos perfis após a queima. É possível observar que as partículas de vidro sofreram modificações físicas visíveis a $1000{ }^{\circ} \mathrm{C}$, o que resultou o overfiring. Através da microscopia ótica (Figura 15), consegue-se observar mais notoriamente os poros ocasionados nas partículas de vidro. A Figura 15(a) apresenta o corpo-de-prova analisado com a incorporação de vidro sinterizado a $800{ }^{\circ} \mathrm{C}$. É possível observar interação entre a partícula de vidro e a matriz cerâmica. A $900{ }^{\circ} \mathrm{C}$, Figura 15(b), já nota-se uma transformação na coloração da partícula de vidro, e a Figura 15 (c) apresenta o corpo-de-prova sinterizado a $1000{ }^{\circ} \mathrm{C}$ e aparições surgimento de poros.

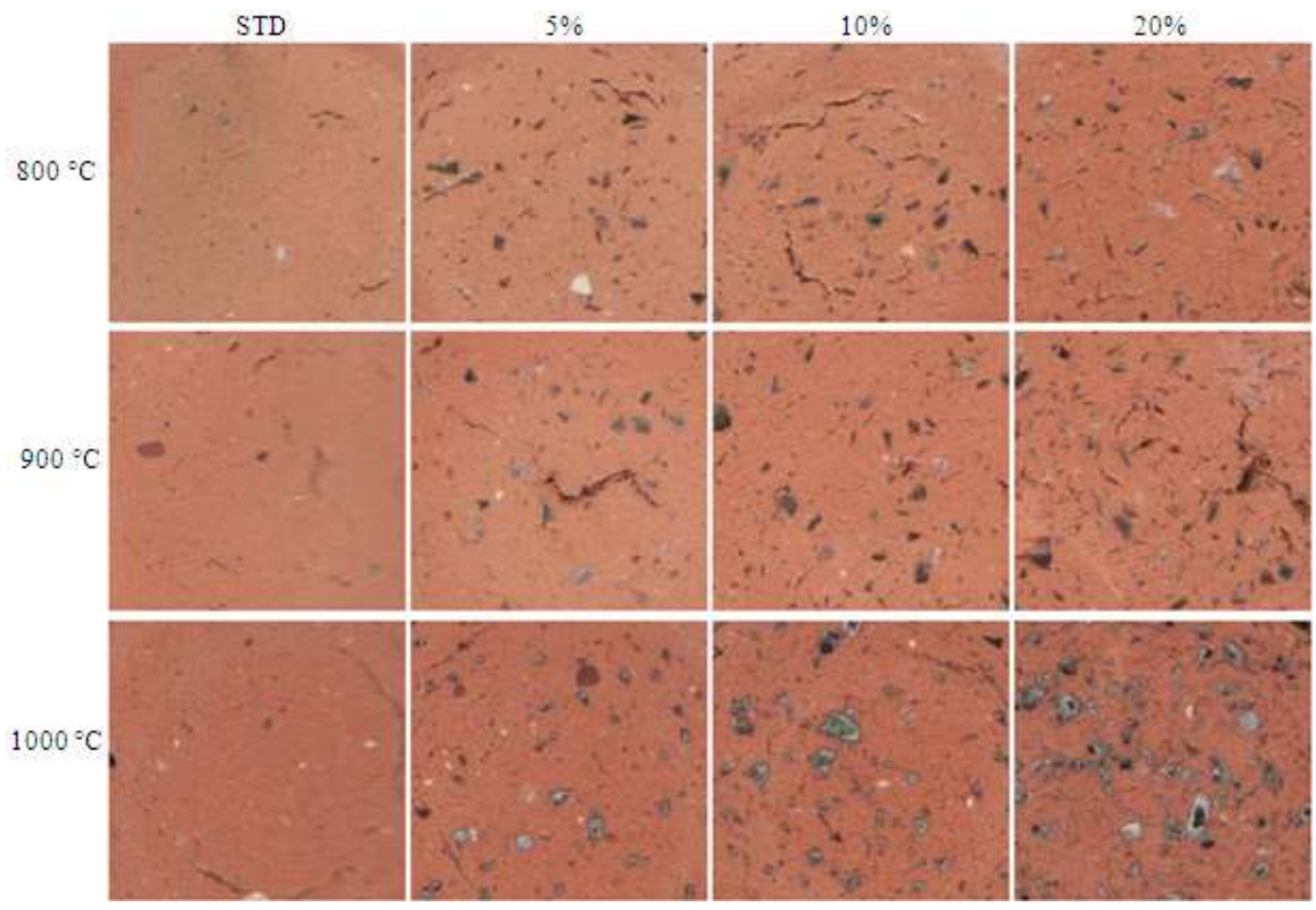

Figura 14: Análise visual do perfil dos corpos-de-prova. 


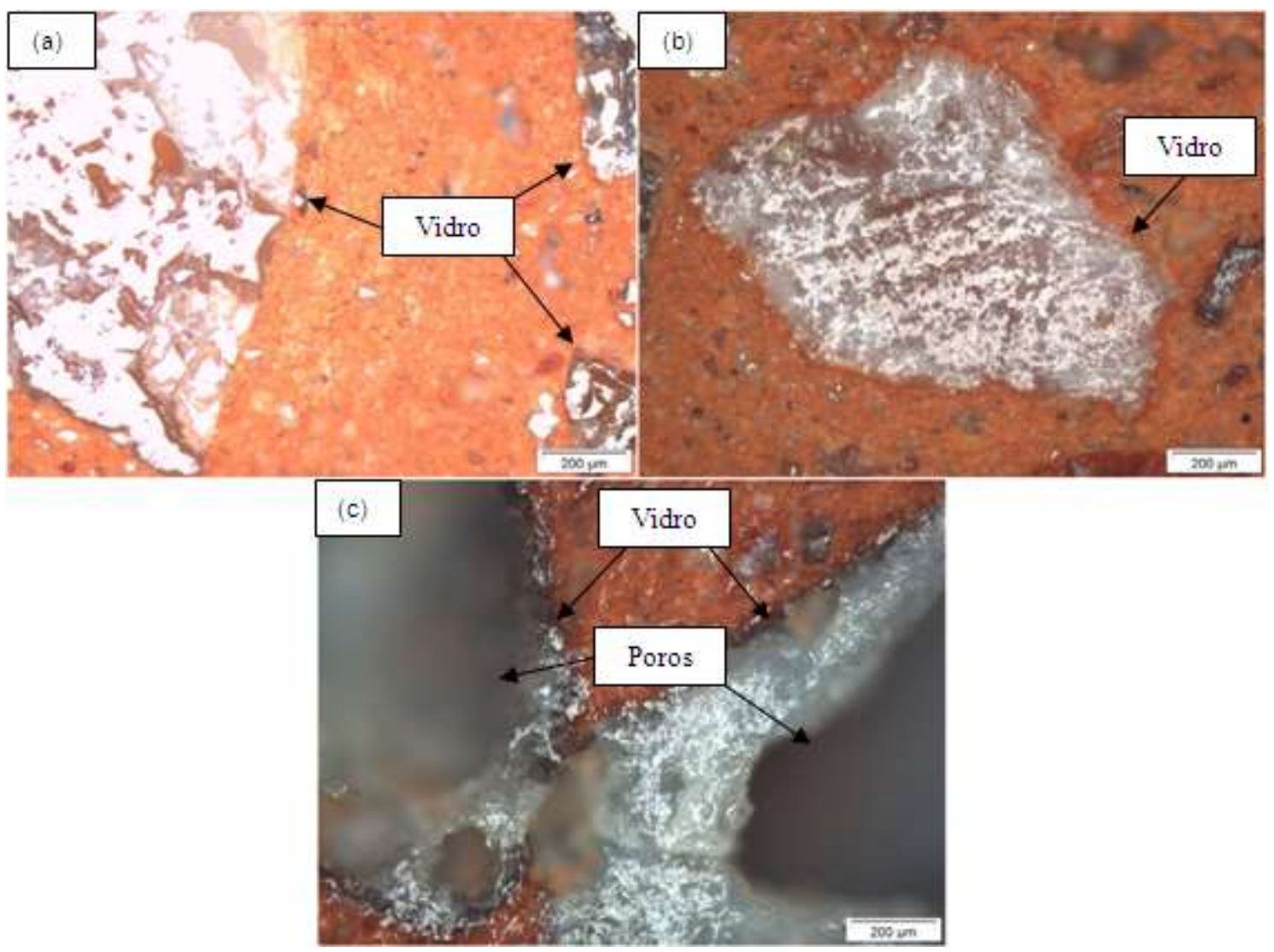

Figura 15: Imagem obtida por microscopia ótica da formulação F3: (a) $800{ }^{\circ} \mathrm{C}$, (b) $900{ }^{\circ} \mathrm{C}$ e (c) $1000{ }^{\circ} \mathrm{C}$.

\section{CONCLUSÕES}

Um estudo foi realizado para se avaliar o efeito da adição de resíduo de vidro nas propriedades tecnológicas de uma massa de cerâmica de alvenaria. Independentemente do teor de adição do resíduo e da temperatura testada, não foi identificada a formação de novas fases cristalinas. No entanto, a adição de vidro interferiu significativamente nas propriedades tecnológicas avaliadas. A retração de secagem foi reduzida de $\sim 8 \%$ da massa cerâmica padrão para $\sim 6 \%$ na formulação contendo $20 \%$ de adição de resíduo de vidro. Esta redução ajuda a diminuir a tendência ao surgimento de trincas de secagem. A $900{ }^{\circ} \mathrm{C}$ a retração de queima é a mesma que o valor da massa padrão, mas a $1000{ }^{\circ} \mathrm{C}$ a retração de queima aumentou de cerca de $3 \%$ para aproximadamente $4 \%$ para $20 \%$ de adição de resíduo. Isto significa maior possibilidade de variação dimensional nas peças queimadas. A absorção de água ficou praticamente invariável com o teor de adição de resíduo à massa cerâmica. Entretanto, a resistência à compressão foi reduzida com a adição de resíduo de vidro. Ainda assim, a composição com adição de $20 \%$ de resíduo de vidro sinterizada a $900{ }^{\circ} \mathrm{C}$ alcançou valor de $6 \mathrm{MPa}$. Embora a $1000{ }^{\circ} \mathrm{C}$ várias propriedades melhoraram, o aspecto visual das peças mostrou a ocorrência de overfiring, que leva ao surgimento de bolhas e deformação. Assim, pode-se dizer que a adição de até $20 \%$ de resíduo de vidro à massa cerâmica para alvenaria sinterizada a $900{ }^{\circ} \mathrm{C}$ apresenta valores aceitáveis das propriedades tecnológicas avaliadas, com a vantagem de reduzir a tendência ao surgimento de trincas de secagem e à variação dimensional, além de contribuir para a redução de uso de matérias-primas virgens e de se dar um destino racional a um resíduo.

\section{AGRADECIMENTOS}

Os autores agradecem ao CNPq e a CAPES e a todas as empresas que colaboraram direta ou indiretamente para o desenvolvimento deste trabalho.

\section{BIBLIOGRAFIA}

[1] GODINHO, K.O., RABELO, T.R., HOLANDA, J.N.F., et al., "Incorporação de resíduo de vidro em cerâmica vermelha”, In: Anais do $48^{\circ}$ Congresso Brasileiro de Cerâmica. pp.1-10, Curitiba, PR, Julho, 2004. 
[2] RAUPP-PEREIRA, F., HOTZA, D., SEGADÃES, A.M., et al., "Ceramic formulations prepa-red with industrial wastes and natural sub-products", Ceramics International, v. 32, n.2, pp. 173-179, 2006 doi:10.1016/j.ceramint.2005.01.014.

[3] ANDREOLA, F., BARBIERI, L., LANCELLOTTI, I., et al., "Recycling of industrial wastes in ceramic manufacturing: State of art and glass case studies", Ceramics International, v. 42, n. 12, pp. 13333-13338, Sep. 2016.

[4] GODINHO, K.O., HOLANDA, J.N.F., SILVA, A.G.P. "Efeito da adição de vidro sobre proprieda-des de queima de uma argila vermelha", In: Anais do $49^{\circ}$ Congresso Brasileiro de Cerâmica, pp. 1-12, São Pedro, SP. Junho, 2005.

[5] SANTOS, W.J. "Caracterização de vidros planos transparentes comerciais", Scientia Plena, v.5, n.2, pp. $1-5,2009$.

[6] GALVÃO, A.C.P., FARIAS, A.C.M., MENDES, J.U.L., "Characterization of waste of soda-lime glass generated from lapping process to reuse as filler in composite materials as thermal insulation", Cerâmica (São Paulo), v.61, n.359, pp. 367-373, July/Sept. 2015. doi:10.1590/0366-69132015613591987.

[7] EL-NAGGAR, M.R., EL-DESSOUKY, M.I., "Re-use of waste glass in improving properties of metakaolin-based geopolymers: Mechanical and microstructure examinations" Construction and Building Materials, v.132, pp. 543-555, Feb. 2017.

[8] GODINHO, K.O., HOLANDA, J.N.F., SILVA, A.G.P. "Obtenção e avaliação de propriedades tecnológicas de corpos cerâmicos à base de argila e vidros reciclados", Cerâmica (São Paulo), v.51, n.320, pp. 419427, Out./Dez. 2005.

[9] COSTA, F.B., TEIXEIRA, S.R., SOUZA, A.E., et al., "Recycling of glass cullet as aggregate for clays used to produce roof tiles", Matéria (Rio J.), v.14, n.4, pp. 1146-1153, 2009.

[10] ELICHE-QUESADA, D., FELIPE-SESÉ, M.A., LÓPEZ-PÉREZ, J.A., et al., "Characterization and evaluation of rice husk ash and wood ash in sustainable clay matrix bricks", Ceramics International, v.43, n.1, pp. 463-475, Jan, 2017.

[11] ZHANG, L. "Production of bricks from waste materials - A review", Construction and Building Materials, v.47, pp. 643-655, Oct. 2013. doi:10.1016/j.conbuildmat.2013.05.043.

[12] ADAZABRA, A.N., VIRUTHAGIRI, G., SHANMUGAM, N., "Infrared analysis of clay bricks incorpo-rated with spent shea waste from the shea butter industry", Journal of Environmental Management, v.191, pp. 66-74, 2017.

[13] KAZMI, S.M.S., ABBAS, S., SALEEM, M.A., et al., "Manufacturing of sustainable clay bricks: Utilization of waste sugarcane bagasse and rice husk ashes", Construction and Building Materials, v.120, pp. 2941, Sep. 2016.

[14] MEDEIROS, E.N.M., SPOSTO, R.M., NEVES, G.A., et al., "Incorporação de cinza de lenha, lodo de estação de tratamento de água e cinza de casca de arroz em massa cerâmica. Utilização da técnica de planejamento", Cerâmica (São Paulo), v.56, n.340, pp. 399-404, Out./Dez. 2010.

[15] MUÑOZ V.P., MORALES O.M.P., LETELIER G.V., et al., Fired clay bricks made by adding wastes: Assessment of the impact on physical, mechanical and thermal properties, Construction and Building Materials, v.125, pp. 241-252, Oct. 2016.

[16] TAHA, Y., BENZAAZOUA, M., HAKKOU, R., et al., "Natural clay substitution by calamine processing wastes to manufacture fired bricks", Journal of Cleaner Production, v.135, pp. 847-858, Nov. 2016. doi:10.1016/j.jclepro.2016.06.200.

[17] WEIZENMANN, M., BRUXEL, F.R., SANTANA, E.R.R., et al., "Avaliação da incorpo-ração de resíduo de gemas na massa cerâmica vermelha - um estudo de caso", Cerâmica (São Paulo), v.59, n.351, pp. 442-447, 2013.

[18] NANDI, V.S., RAUPP-PEREIRA, F., MONTEDO, O.R.K., et al., "The use of ceramic sludge and recycled glass to obtain engobes for manufacturing ceramic tiles", Journal of Cleaner Production, v.86, pp. 461470, Jan. 2015.

[19] LORYUENYONG, V., PANYACHAI, T., KAEWSIMORK, K., et al., "Effects of recycled glass substitution on the physical and mechanical properties of clay bricks", Waste Management, v.29, n.10, pp. 27172721, Oct. 2009. 
[20] PONTIKES, Y., ESPOSITO, L., TUCCI, A., et al., "Thermal behaviour of clays for traditional ceramics with soda-lime-silica waste glass admixture", Journal of the European Ceramic Society, v.27, n.2-3, pp. 1657-1663, 2007.

[21] PHONPHUAK, N., KANYAKAM, S., CHINDAPRASIRT, P. "Utilization of waste glass to enhance phys-ical-mechanical properties of fired clay brick", Journal of Cleaner Production, v.112, pp. 3057-3062, Jan. 2016.

[22] ABNT - Associação Brasileira de Normas Técnicas, NBR 15270-3, Componentes cerâmicos Parte 3: blocos cerâmicos para alvenaria estrutural e de vedação - Métodos de ensaio, 27p, Rio de Janeiro, RJ, 2005.

[23] MORAIS, A.S.C., COSTA CALDAS, T.C., MONTEIRO, S.N., et al., "Characterization of Fluorescent Lamp Glass Waste Powders", Materials Science Forum, v.727-728, pp. 1579-1584, 2012.

[24] VIEIRA, C.M.F., FEITOSA, H.S., MONTEIRO, S.N. “Avaliação da Secagem de Cerâmica Vermelha Através da Curva de Bigot”, Cerâmica Industrial, v.8, n.1, pp. 42-46, Jan./Fev. 2003.

[25] KHALILI, K., HEYDARI, M., KHALILI, M.S. "Drying Clay Bricks with Variable Young's Modulus", Procedia Technology, v.12, pp. 382-387, 2014.

[26] YATAGANBABA, A., KURTBAŞ, I., "A scientific approach with bibliometric analysis related to brick and tile drying: A review", Renewable and Sustainable Energy Reviews, v.59, pp. 206-224, Jun.2016.

[27] MYMRIN, V., KLITZKE, W., ALEKSEEV, K., et al., "Red clay application in the utilization of paper production sludge and scrap glass to fabricate ceramic materials", Applied Clay Science, v.107, pp. 28-35, Apr. 2015.

[28] CHRISTOGEROU, A., KAVAS, T., PONTIKES, Y., et al., "Use of boron wastes in the production of heavy clay ceramics", Ceramics International, v.35, n.1, pp. 447-452, Jan. 2009.

[29] ABNT - Associação Brasileira de Normas Técnicas, NBR 15270-1, Componentes cerâmicos. Parte 1: Blocos cerâmicos para alvenaria de vedação - Terminologia e requisitos, 15p., Rio de Janeiro, RJ, 2005.

[30] RIELLA, H.G. Cerâmica: dos minerais à porcelana, TecArt, São Paulo, SP, 2010.

[31] BRAGANÇA, S.R., BERGMANN, C.P., "Utilização de pó de vidro em uma massa industrial de cerâmica branca", In: Anais do XVI Congresso Brasileiro de Engenharia e Ciência dos Materiais, CBECIMAT, Porto Alegre, RS, 2004.

[32] PORTO, V.S., CAVALCANTI, M.S.L., ARAÚJO, A.M.B., et al., "Substituição parcial do feldspato pelo resíduo de vidro plano em massas para cerâmica branca", In: $56^{\circ}$ Congresso Brasileiro de Cerâmica; $1^{\circ}$ Congresso Latino-Americano de Cerâmica; IX Brazilian Symposium on Glass and Related Materials, Curitiba, PR, pp. 1189-1198, Jun.2012.

[33] CALDAS, T.C.C. "Reciclagem de resíduo de vidro plano em cerâmica vermelha", Dissertação de Msc., Universidade Estadual do Norte Fluminense Darcy Ribeiro - UENF, Rio de Janeiro, RJ, Brasil, 2012.

\section{ORCID}

Alexandre Zaccaron

Rafael Guelfi Frizzo

Elton Torres Zanoni

Oscar Rubem Klegues Montedo

Adriano Michael Bernardin

Michael Peterson

Fábio Rosso

Vitor de Souza Nandi https://orcid.org/0000-0002-5120-9416

https://orcid.org/0000-0001-5064-1218

https://orcid.org/0000-0003-3117-7178

https://orcid.org/0000-0002-3350-6732

https://orcid.org/0000-0003-4132-5007

https://orcid.org/0000-0002-5002-1294

https://orcid.org/0000-0001-9540-8890

https://orcid.org/0000-0001-9893-4212 